\title{
APROVEITAMENTO AGROINDUSTRIAL DE RESÍDUOS PROVENIENTES DO ABACAXI 'PÉROLA' MINIMAMENTE PROCESSADO
}

\author{
P. C. C. LIMA ${ }^{1, *}$, B. S. SOUZA ${ }^{2}$, A. T. SANTINI ${ }^{2}$ e D. C. OLIVEIRA ${ }^{3}$ \\ ${ }^{1}$ Universidade Federal de Viçosa, UFV \\ ${ }^{2}$ Instituto Federal de Educação, Ciência e Tecnologia do Sul de Minas Gerais, campus Muzambinho - IFSMG \\ ${ }^{3}$ Universidade Federal de Lavras, UFLA \\ paula.c.lima@ufv.br
}

Submetido 20/10/2016 - Aceito 26/05/2017

DOI: $10.15628 /$ holos. 2017.5238

\section{RESUMO}

Um dos principais obstáculos no desenvolvimento da indústria de processamento mínimo de frutas e hortaliças é o fato de que gerarem grande quantidade de resíduos orgânicos, os quais muitas vezes, não possuem um destino específico, tornando-se contaminantes ambientais. Sendo assim, o objetivo deste é estudar alternativas para o aproveitamento das cascas de abacaxis 'Pérola' minimamente processados. Do resíduo da casca foram elaboradas duas receitas de doces, enquanto que do suco obtido do processamento

do resíduo foi elaborado uma geleia. Os produtos elaborados foram avaliados quanto à composição centesimal e sensorialmente, usando escala hedônica de 5 pontos para o parâmetro sabor e aparência. Os resultados mostram que os produtos elaborados a partir da casca apresentaram maior valor nutricional. $O$ teste sensorial indicou que todos os produtos elaborados, obtiveram aceitabilidade por parte dos julgadores, com índices superiores a $80 \%$.

PALAVRAS-CHAVE: Ananas comosus L. Merril, resíduo vegetal, alimentação humana, análise sensorial.

\section{UTILIZATION OF AGROINDUSTRIAL WASTE FROM PINEAPPLE 'PÉROLA' MINIMALLY PROCESSED}

\begin{abstract}
A major barrier in the development of minimally processed fruit and vegetable industry is the fact that generate large quantities of organic waste, which often, do not have a specific destination, becoming environmental contaminants. Then, the goal of this work is study alternatives for the exploitation of the peels of pineapple 'Pérola' minimally processed. The residues of the peel were prepared two sweet recipes, while the
\end{abstract}

waste obtained from the processing juice was prepared a jelly. The processed products were evaluated about the chemical composition and sensorially, using hedonic scale of 5 points for flavor and appearance parameter. The results show that products prepared from the peel presented a higher nutritional value. The sensorial test indicated that all processed products, showed acceptability for panelists, with rates above $80 \%$.

KEYWORDS: Ananas comosus L. Merril, vegetable waste, human nutrition, sensory analysis. 


\section{INTRODUÇÃO}

O abacaxi (Ananas comosus L. Merril) é uma planta de clima tropical, monocotiledônea, herbácea e perene da família Bromeliácea que tem grande aceitação em todo o mundo em sua forma natural e industrializada, agradando aos olhos, ao paladar e ao olfato (Crestani, Barbieri, Hawerrothl, Carvalho \& Oliveira, 2010). A composição química do abacaxi varia principalmente de acordo com a época do ano em que é produzido, variedade e condições climáticas. Mas para Waughon \& Pena (2006), seu valor nutricional depende, principalmente, dos sólidos solúveis, das vitaminas e minerais presentes.

O abacaxi é uma das frutas tropicais mais populares do mundo e tem o Brasil como um dos principais centros produtores da espécie (Rogério et al., 2007). As cultivares mais plantadas no Brasil são 'Pérola' e 'Smooth Cayenne', sendo a 'Pérola' considerada insuperável para o consumo ao natural, graças a sua polpa suculenta e saborosa (Gonçalves \& Carvalho, 2000).

Segundo Gondim, Moura, Dantas, Medeiros e Santos (2005), a fome e o desperdício de alimentos são dois dos maiores problemas que o Brasil enfrenta, constituindo-se em um dos paradoxos de nosso país. Devido ao nosso hábito alimentar, cascas de frutas, folhas e talos de hortaliças são jogados no lixo. O que a maioria das pessoas não sabe é que estes alimentos podem conter nutrientes como vitaminas, carboidratos, proteínas e fibras em quantidades superiores à da polpa e que podem ser aproveitados, diminuindo os gastos com alimentação e melhorando a qualidade nutricional do cardápio e reduzindo o desperdício.

Os principais resíduos do abacaxi minimamente processado são a coroa, a casca, as extremidades e o cilindro central. As cascas e o cilindro central do abacaxi 'Pérola' correspondem a 38\% do peso do fruto (Sarzi, Durigan \& Rossi Junior, 2002). Quando do processamento industrial, cascas, talos, coroas e cilindros são considerados rejeitos da indústria e ainda são fornecidos para os animais de forma empírica (Rogério et al, 2007). Porém, tanto a casca como o cilindro central do abacaxi podem ser considerados boa fonte de fibra alimentar, que apresenta um papel importante no processo digestivo, porém, as duas partes do fruto são pobres em pectina (Botelho, Conceição \& Carvalho, 2002). Em outro estudo realizado, verificou-se que a casca do abacaxi apresenta mais proteínas, lipídeos, fibras, cálcio, potássio do que na polpa (Gondim et al., 2005).

O desperdício de alimentos na cadeia alimentar tem causas econômicas, políticas, culturais e tecnológicas, que abrangem as principais etapas da cadeia de movimentação: produção, transporte, comercialização, sistema de embalagem e armazenamento (Castro, 2002). Em vista disso, na indústria de alimentos que produz grande volume de resíduos resultantes da produção, preparo e consumo de alimentos. A utilização e o destino apropriado destes resíduos vêm se tornando uma preocupação nos últimos anos (Moretti \& Machado, 2006).

Como o homem necessita, de qualquer modo, de uma alimentação sadia, rica em nutrientes, isto pode ser alcançado com partes de alimentos que normalmente são desprezadas (Gondim et al., 2005). Dentre as várias alternativas já existentes para evitar desperdício, destacase o aproveitamento de partes usualmente não consumíveis em bolos, geleias, doces, pães entre outros. Essas alternativas de aproveitamento são importantes, pois as partes consideradas usualmente não consumíveis também apresentam valor nutricional relevante (Damiani et al., 2011). Na tecnologia de alimentos, a produção de doces é uma técnica bem estabelecida e se tornou uma alternativa para a conservação de matérias-primas, pois reduz perdas dos alimentos 
excedentes, aumenta vida útil, garante certas frutas fora do período da safra e oportuniza o consumo em regiões não produtoras, aumentando sua disponibilidade (Santana \& Oliveira, 2005).

Com o objetivo de diminuir o desperdício de alimentos e dar um destino aos resíduos produzidos pelo processamento mínimo do abacaxi 'Pérola', o presente trabalho apresenta alternativas de aproveitamento deste resíduo na confecção de subprodutos, além de incentivar o aproveitamento integral das frutas, analisando as diferentes partes que compõem o abacaxi, identificando através da sua composição os seus principais componentes nutricionais.

\section{METODOLOGIA}

\subsection{Matéria-Prima}

Para a confecção dos subprodutos foram utilizados abacaxis da cultivar Pérola adquiridos no ponto de maturação "pintado" (Ceagesp, 2000). Os frutos foram levados para setor de Agroindústria do Instituto Federal - Sul de Minas Gerais, Campus Muzambinho onde foram lavados com detergente e enxaguados com solução de cloro a 50 ppm, assim como todos os utensílios utilizados no processamento do material, como placas de corte, bancadas e facas. 0 processamento consistiu no descascamento e retirada do cilindro central, tendo as seguintes partes: casca, polpa e cilindro central. O resíduo foi obtido através da homogeneização da casca com água na proporção de 1:2 e posteriormente foi coado, obtendo-se uma massa da casca. Os subprodutos obtidos foram utilizados para a confecção de receitas, bem como as amostras foram levadas ao laboratório de Bromatologia e Água, para a realização da análise centesimal das seguintes partes constituintes do fruto: casca, polpa, cilindro central e suco.

\subsection{Elaboração das receitas}

\subsubsection{Processo de elaboração do doce pastoso}

Após a obtenção dos subprodutos, o doce pastoso foi elaborado utilizando os seguintes ingredientes e quantidades:

\begin{tabular}{c|c}
\hline INGREDIENTES & QUANTIDADE \\
\hline Suco da casca de abacaxi & $240 \mathrm{~mL}$ \\
\hline Massa da casca & $240 \mathrm{~g}$ \\
\hline Coco ralado & $80 \mathrm{~g}$ \\
\hline Açúcar & $320 \mathrm{~g}$ \\
\hline
\end{tabular}

Quadro 1: Formulação do doce pastoso confeccionado com de casca de abacaxi.

Todos os ingredientes foram colocados em uma panela de inox e levados ao fogo para cocção por cerca de 1 hora e 30 minutos a $90^{\circ} \mathrm{C}$, até atingir o ponto de soltar do fundo da panela. Seguindo o processo de Miguel, Albertini, Begiato, Dias \& Spoto (2008), ao final, os produtos foram acondicionados a quente $\left(85^{\circ} \mathrm{C}\right)$ em embalagens de vidro, previamente esterilizadas a 100 ${ }^{\circ} \mathrm{C} / 30$ minutos, com capacidade para $268 \mathrm{~mL}$ e fechadas com tampa de metal. $\mathrm{O}$ tratamento térmico foi efetuado em banho-maria a $100{ }^{\circ} \mathrm{C}$ por 15 minutos. Em seguida, os frascos foram 
invertidos para promover a esterilização das tampas por 15 minutos, resfriados à temperatura ambiente, lacrados e armazenados na mesma temperatura (Doce 1).

\subsubsection{Processo de elaboração do doce de enrolar}

Após a obtenção dos subprodutos, o doce pastoso foi elaborado utilizando os seguintes ingredientes e quantidades:

\begin{tabular}{c|c}
\hline INGREDIENTES & QUANTIDADE \\
\hline Suco da casca de abacaxi & $240 \mathrm{~mL}$ \\
\hline Massa da casca & $240 \mathrm{~g}$ \\
\hline Coco ralado & $80 \mathrm{~g}$ \\
\hline Açúcar & $320 \mathrm{~g}$ \\
\hline Margarina & $12 \mathrm{~g}$ \\
\hline 1 gema de ovo & $20 \mathrm{~g}$
\end{tabular}

Quadro 2: Formulação do doce de enrolar confeccionado com de casca de abacaxi.

Todos os ingredientes foram colocados em uma panela de inox e levados ao fogo para cocção por cerca de 1 hora e 30 minutos a $90^{\circ} \mathrm{C}$, até atingir o ponto de soltar do fundo da panela. Posteriormente, após o resfriamento em temperatura ambiente o doce foi enrolado em bolinhas, passadas no coco ralada e colocado em forminhas de papel (Doce 2).

\subsubsection{Processo de elaboração da geleia}

Após a obtenção dos subprodutos, a geleia foi elaborada utilizando os seguintes ingredientes e quantidades:

\begin{tabular}{c|c}
\hline INGREDIENTES & QUANTIDADE \\
\hline Suco da casca de abacaxi & $8 \mathrm{~L}$ \\
\hline Açúcar & $4 \mathrm{Kg}$ \\
\hline Pectina Comercial & $100 \mathrm{~g}$ \\
\hline
\end{tabular}

Quadro 3: Formulação da geleia confeccionada com de casca de abacaxi.

Ao suco obtido foi acrescentado $2 / 3$ da quantidade de açúcar utilizado e levado, em panela de inox, para cocção, mexendo periodicamente. Decorridos alguns minutos adicionou-se o restante do açúcar e a pectina comercial, continuando a mexer periodicamente até obter-se o ponto de geleia com concentração final de sólidos solúveis de $54,8{ }^{\circ}$ Brix. As geleias foram envasadas a quente $\left(85^{\circ} \mathrm{C}\right)$ em embalagens de vidro previamente esterilizadas a $100{ }^{\circ} \mathrm{C} / 30 \mathrm{~min}$, com capacidade para $268 \mathrm{~mL}$, previamente higienizadas em água clorada a 150 ppm e fechadas com tampa de metal. Em seguida, realizou-se uma termo-inversão, por 3 minutos, e resfriamento em água. As geleias foram identificadas e armazenadas à temperatura ambiente para a realização das avaliações.

\subsection{Avaliações}




\subsubsection{Avaliações físico-químicas}

Os métodos utilizados para as avaliações dos doces confeccionados com casca de abacaxis foram: umidade, com o emprego do calor em estufa ventilada à temperatura de $105^{\circ} \mathrm{C}$, com verificações esporádicas até obtenção de peso constante (AOAC, 2012); fibra bruta pelo método gravimétrico após a hidrólise ácida, (Kamer \& Ginkel, 1952); proteína bruta, determinada do teor de nitrogênio por destilação em aparelho de Microkjedahl (AOAC, 2012); extrato etéreo (lipídios) usando o aparelho de extração contínua tipo Soxhlet (AOAC, 2012); resíduo mineral ou fração de cinzas determinado gravimetricamente avaliando a perda de peso do material submetido ao aquecimento a $550{ }^{\circ} \mathrm{C}$ em mufla (AOAC, 2012); fração glicídica (carboidratos) determinada através do cálculo: \% F.G. $=100-(\mathrm{U}+\mathrm{EE}+\mathrm{P}+\mathrm{F}+\mathrm{C})$, sendo os valores expressos em g.100g ${ }^{-1}$. O valor calórico foi calculado usando os fatores de conversão de Atwater: $4 \mathrm{Kcal} / \mathrm{g}$ para proteínas, 4 $\mathrm{Kcal} / \mathrm{g}$ para carboidratos e $9 \mathrm{kcal} / \mathrm{g}$ para lipídios, conforme Osborne \& Voogt (1978).

Para a análise da geleia foram empregados os seguintes métodos: umidade, com o emprego do calor em estufa ventilada à temperatura de $105^{\circ} \mathrm{C}$, com verificações esporádicas até obtenção de peso constante (AOAC, 2012); teor de sólidos solúveis (SS) determinado em refratômetro digital (Atago PR 101) e os resultados expressos em oBrix (AOAC, 2012); acidez titulável expressa em gramas de ácido cítrico por 100 gramas de polpa, em que cada amostra de polpa homogeneizada foi titulada com solução padronizada de hidróxido de sódio a $0,1 \mathrm{M}$, até a amostra alcançar pH 8,1 (AOAC, 2012) e pH determinado utilizando-se potenciômetro (AOAC, 2012).

\subsubsection{Avaliações microbiológicas}

Os métodos utilizados para as avaliações dos doces confeccionados com casca de abacaxis foram contagem de coliformes, Staphylococcus e Salmonella, e na geleia foram feitas as contagens de fungos e leveduras pelo métodos descritos por Silva, Junqueira \& Silveira (2007).

\subsubsection{Avaliações de aceitabilidade}

Foram utilizados 88 provadores não treinados para o Doce 1, 85 para o Doce 2 e 65 para a Geleia, entre eles, funcionários, professores e alunos do Instituto. $O$ teste de aceitabilidade foi realizado através de escala hedônica de cinco pontos (gostei muito; gostei; indiferente; não gostei; não gostei extremamente) (Meilgaard, Civille \& Carb, 1999), onde foi oferecida uma amostra de um doce e questionado quanto o provador gostou ou desgostou do sabor e da aparência. Para a geleia foi avaliado apenas o parâmetro sabor e as amostras foram servidas em biscoito de água e sal aos provadores, à temperatura ambiente. A aceitabilidade global foi determinada pelas avaliações 'gostei' e gostei muito' para as variáveis sabor e aparência. Ambos os parâmetros foram avaliados entre provadores não treinados do sexo feminino e masculino e em relação a três faixas etárias: Faixa $1-15$ a 30 anos, Faixa $2-31$ a 45 anos e Faixa $3-46$ a acima de 60 anos.

\subsubsection{Análise estatística}

As médias dos parâmetros analisados referentes aos produtos foram agrupadas segundo o teste de Tukey, em nível de $5 \%$ de probabilidade do erro. As análises estatísticas foram realizadas 
utilizando o software Sisvar (Ferreira, 2011). Para a confecção dos gráficos referentes às avaliações sensoriais foi utilizado o programa SigmaPlot.

\section{RESULTADOS E DISCUSSÃO}

\subsection{Caracterização das partes do abacaxi e seus produtos}

As porcentagens referentes a cada parte do fruto de abacaxizeiro foram: casca $=33,7 \%$, polpa $=60 \%$ e cilindro central $=6,3 \%$, dados próximos aos encontrados por Sarzi et al. (2002), quando calcularam o rendimento de polpa de abacaxi minimamente processado. A Tabela 1 contém os resultados da composição centesimal referentes às partes que compõe o fruto do abacaxi. Os teores de umidade diferiram significativamente, em que o suco da casca apresentou o maior teor de umidade, seguido pelo miolo, polpa e casca, os dados referentes à umidade da polpa são semelhantes aos de Gondim et al. (2005), enquanto que o teor de umidade encontrado na casca está acima do valor encontrado pelo autor supracitado que é $78,13 \%$.

Os teores médios de fração de cinzas dos produtos apresentaram diferenças significativas entre si, como consta na Tabela 1, em que a casca apresentou o maior teor de cinzas em relação aos demais produtos, porém o valor está abaixo de $1,03 \mathrm{~g} .100 \mathrm{~g}^{-1}$ encontrados por Gondim et al. (2005). Em relação aos teores médios de proteína bruta apresentados na tabela 1, também há diferença estatística onde casca e polpa apresentam os maios teores, 0,84 e 0,64 g.100g $\mathrm{g}^{-1}$ respectivamente. Estes valores são inferiores aos encontrados por Gondim et al. (2005), 1,45 e 1 g. $100 \mathrm{~g}^{-1}$, respectivamente. Os teores de extrato etéreo apresentados na Tabela 1 mostraram diferenças estatística, em que a casca e a polpa apresentam maiores teores, tais dados são contrastantes com os de Gondim et al. (2005) que observaram maior teor para casca $(0,55$ g. $100 \mathrm{~g}^{-1}$ ) e menor para polpa $\left(0 \mathrm{~g} \cdot 100 \mathrm{~g}^{-1}\right)$.

Em relação aos teores de fibras alimentares (Tabela 1), houve diferença estatística, em que os teores encontrados na casca foram superiores aos demais produtos, sendo que os teores encontrados para casca e polpa são inferiores aos encontrados por Gondim et al. (2005), que são 3,89 e $1 \mathrm{~g} .100 \mathrm{~g}^{-1}$, respectivamente. Quanto aos dados relacionados aos teores de carboidratos e calorias, também apresentaram diferença estatística, onde os maiores valores foram observados na polpa, em que este dado difere de Gondim et al. (2005), uma vez que encontraram maiores teores de carboidratos e calorias na casca do abacaxi.

$\mathrm{Na}$ avaliação da composição centesimal da casca de abacaxi, Santos, Ciabotti, Pereira, Gonçalves \& Campagnol (2010) destacam valores médios de 0,3\% de lipídios, teor de proteínas de $1,08 \%$ e teor de fibras de $2,06 \%$. Segundo os autores, esses índices tornam tal subproduto bastante atrativo para a alimentação humana podendo ser utilizado, por exemplo, como auxiliar no fornecimento de aminoácidos essenciais dado ao seu teor de proteínas e, ainda, fonte alternativa de fibra para alimentação configurando-se, portanto, como complemento alimentar de baixo valor nutricional. Costa, Felipe, Maia, Brasil e Hernandez (2007) apontam teores ainda mais elevados em casca e bagaço de abacaxi, com valores de fibra insolúvel e solúvel de 7,52\% e $5,89 \%$, respectivamente.

Estas diferenças podem ser explicadas pela metodologia empregada na análise ou na separação das partes do fruto, pois neste trabalho houve a extração do suco da casca por meio da homogeneização com água, obtendo-se assim mais um resíduo. Houve também a separação 
do cilindro central da polpa gerando outro resíduo. Tais procedimentos podem gerar divergências em relação aos dados encontrados na literatura.

Também podem ser explicadas pela variação grande na composição química do abacaxi de acordo com a época em que é produzido e também pelo fato de ser constituído de 100 a 200 frutilhos fundidos entre si sobre um eixo central, o que leva a ausência de homogeneidade na composição química de suas diversas partes (Bleinroth, 1978).

Tabela 1: Composição centesimal das partes do Abacaxi ‘Pérola’.

\begin{tabular}{|c|c|c|c|c|c|c|c|}
\hline \multirow{2}{*}{$\begin{array}{l}\text { Produtos } \\
\text { (Abacaxi) }\end{array}$} & \multicolumn{6}{|c|}{ Composição centesimal $\left(\mathrm{g} \cdot 100 \mathrm{~g}^{-1}\right)$} & \multirow{2}{*}{$\begin{array}{l}\text { Calorias } \\
\left(\text { Kcal. 100g } \mathrm{g}^{-1}\right)\end{array}$} \\
\hline & Umidade & $\begin{array}{c}\text { Fração de } \\
\text { Cinzas }\end{array}$ & $\begin{array}{c}\text { Proteína } \\
\text { Bruta }\end{array}$ & $\begin{array}{l}\text { Extrato } \\
\text { Etéreo }\end{array}$ & Fibra Bruta & Carboidratos & \\
\hline Polpa & $\begin{array}{l}85,43 \text { c } \\
\pm 0,51^{*}\end{array}$ & $\begin{array}{c}0,32 \mathrm{~b} \\
\pm 0,01^{*}\end{array}$ & $\begin{array}{c}0,64 \mathrm{~b} \\
\pm 0,04^{*}\end{array}$ & $\begin{array}{c}0,26 \mathrm{ab} \\
\pm 0,006^{*}\end{array}$ & $\begin{array}{c}0,81 \mathrm{~b} \\
\pm 0,02^{*}\end{array}$ & $\begin{array}{l}12,46 \text { a } \\
\pm 0,50^{*}\end{array}$ & $\begin{array}{l}55,35 \text { a } \\
\pm 2,11^{*}\end{array}$ \\
\hline Casca & $\begin{array}{l}85,31 \mathrm{c} \\
\pm 0,59^{*}\end{array}$ & $\begin{array}{c}0,54 \text { a } \\
\pm 0,03^{*}\end{array}$ & $\begin{array}{c}0,84 \text { a } \\
\pm 0,01^{*}\end{array}$ & $\begin{array}{c}0,29 \text { a } \\
\pm 0,03^{*}\end{array}$ & $\begin{array}{c}3,47 a \\
\pm 0,15^{*}\end{array}$ & $\begin{array}{c}9,27 b \\
\pm 0,67^{*}\end{array}$ & $\begin{array}{l}45,38 \text { a } \\
\pm 2,89 *\end{array}$ \\
\hline $\begin{array}{l}\text { Cilindro } \\
\text { Central }\end{array}$ & $\begin{array}{l}92,72 \mathrm{~b} \\
\pm 0,72^{*}\end{array}$ & $\begin{array}{c}0,19 c \\
\pm 0,02 *\end{array}$ & $\begin{array}{c}0,39 \mathrm{c} \\
\pm 0,03^{*}\end{array}$ & $\begin{array}{c}0,18 b \\
\pm 0,006^{*}\end{array}$ & $\begin{array}{l}0,00 \mathrm{c} \\
\pm 0,0^{*}\end{array}$ & $\begin{array}{c}6,50 c \\
\pm 0,76^{*}\end{array}$ & $\begin{array}{l}29,15 \text { b } \\
\pm 2,98^{*}\end{array}$ \\
\hline $\begin{array}{l}\text { Suco da } \\
\text { casca }\end{array}$ & $\begin{array}{l}96,25 \text { a } \\
\pm 0,30^{*}\end{array}$ & $\begin{array}{l}0,26 \text { bc } \\
\pm 0,01^{*}\end{array}$ & $\begin{array}{c}0,18 \mathrm{~d} \\
\pm 0,05^{*}\end{array}$ & $\begin{array}{l}0,24 \mathrm{ab} \\
\pm 0,04^{*}\end{array}$ & $\begin{array}{c}0,05 \mathrm{c} \\
\pm 0,02^{*}\end{array}$ & $\begin{array}{c}3,01 \mathrm{~d} \\
\pm 0,32^{*}\end{array}$ & $\begin{array}{l}14,95 \text { c } \\
\pm 0,92^{*}\end{array}$ \\
\hline
\end{tabular}

Médias seguidas de pelo menos uma mesma letra na coluna, não diferem significativamente entre si $(P<0,05) .{ }^{*}$ Erro padrão da média $(n=4)$.

Diante destes resultados e da alta porcentagem de casca gerada no processamento, verifica-se que a utilização da mesma na confecção de doces apresenta-se como uma boa alternativa de aproveitamento deste resíduo, devido ao teor de fibras e de nutrientes, além do baixo valor calórico, como o indicado por Botelho et al. (2002). Borges, Chim, Leitão, Pereira \& Luvielmo (2004) desenvolveram um estudo sobre a viabilidade da utilização de resíduos das indústrias de conserva de abacaxi da região de Pelotas - RS para a produção de suco. O processamento do suco-base foi feito a partir da obtenção das cascas, centros e aparas da fruta e consistiu das etapas de branqueamento, prensagem e filtragem, os autores concluíram que é viável a elaboração de suco de abacaxi a partir de resíduos de sua industrialização.

Entre os produtos gerados a partir de resíduos de frutas advindos da produção agroindustrial, podem ser destacados os doces, que possuem larga aceitação pelos consumidores. De acordo com Goubart (1979), o doce em pasta vem se constituindo, nos últimos anos como uma das melhores opções, tanto para os produtores como para as indústrias. Para os produtores, porque tem nas indústrias uma garantia para a colocação de seu produto. Para indústrias, porque podem usar matéria prima mais barata, por não ser o tipo de produto muito exigente em tremo de uniformidade da fruta.

Em relação a composição centesimal dos doces, de uma maneira geral apresentaram menores teores de umidade, boa quantidade de fibras e lipídeos, além da proteína, matéria mineral e bom teor de carboidratos (Tabela 2), sendo que o doce de enrolar, apresentou 
características químicas superiores em relação ao doce pastoso. Os doces apresentaram bom teor de fibra $\left(3,0\right.$ e 4,7 g.100 $\left.{ }^{-1}\right)$. Segundo Brasil (2012), um alimento com teor mínimo de 3\% de fibra alimentar pode ser considerado uma boa fonte de fibra. Com base nos resultados obtidos, pode-se dizer que os produtos obtidos da casca do abacaxi são boa fonte de fibra.

Os doces confeccionados com casca de abacaxi apresentaram melhor valor nutricional quando comparados com doce elaborado com casca de melão, que apresentou $31,49 \mathrm{~g}^{1} 1 \mathrm{gog}^{-1} \mathrm{de}$ umidade, $1,63 \mathrm{~g} \cdot 100 \mathrm{~g}^{-1}$ de proteína, $0,06 \mathrm{~g} \cdot 100 \mathrm{~g}^{-1}$ de lipídios, $2,94 \mathrm{~g} .100 \mathrm{~g}^{-1}$ de fibras, $61,85 \mathrm{~g} .100 \mathrm{~g}$ ${ }^{1}$ de carboidratos, 0,84 g.100 ${ }^{-1}$ de fração de cinzas e 260,11 Kcal (Miguel et al., 2008) ou cocada branca, que apresentou $3,4 \mathrm{~g} \cdot 100 \mathrm{~g}^{-1}$ de umidade, $1,1 \mathrm{~g} .100 \mathrm{~g}^{-1}$ de proteína, $13,6 \mathrm{~g} .100 \mathrm{~g}^{-1} \mathrm{de}$ lipídios, $81,3 \mathrm{~g} \cdot 100 \mathrm{~g}^{-1}$ de carboidratos, $0,5 \mathrm{~g} \cdot 100 \mathrm{~g}^{-1}$ de fração de cinzas e $449 \mathrm{Kcal}$ (Nepa, 2011).

Tabela 2: Composição centesimal dos doces confeccionados com resíduo de abacaxi ‘Pérola'.

\begin{tabular}{|c|c|c|c|c|c|c|c|}
\hline \multirow{2}{*}{$\begin{array}{c}\text { Doces } \\
\text { (Abacaxi) }\end{array}$} & \multicolumn{6}{|c|}{ Composição centesimal $\left(\mathrm{g} .100 \mathrm{~g}^{-1}\right)$} & \multirow{2}{*}{ 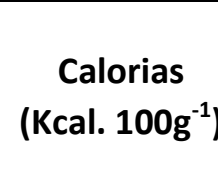 } \\
\hline & Umidade & $\begin{array}{c}\text { Fração de } \\
\text { Cinzas }\end{array}$ & $\begin{array}{c}\text { Proteína } \\
\text { Bruta }\end{array}$ & $\begin{array}{l}\text { Extrato } \\
\text { Etéreo }\end{array}$ & Fibra Bruta & Carboidratos & \\
\hline Doce & 36,81 & 0,44 & 0,73 & 4,31 & 3,02 & 54,70 & 260,45 \\
\hline Pastoso & $\pm 0,33^{*}$ & $\pm 0,007^{*}$ & $\pm 0,02 *$ & $\pm 0,09 *$ & $\pm 0,08^{*}$ & $\pm 0,36^{*}$ & $\pm 0,92^{*}$ \\
\hline Doce & 23,64 & 0,55 & 1,70 & 8,49 & 4,70 & 60,92 & 326,92 \\
\hline de Enrolar & $\pm 0,16^{*}$ & $\pm 0,004^{*}$ & $\pm 0,03^{*}$ & $\pm 0,005^{*}$ & $\pm 0,06^{*}$ & $\pm 0,09 *$ & $\pm 0,31^{*}$ \\
\hline
\end{tabular}

* Erro padrão da média $(n=2)$.

Em relação aos dados de fração de cinzas, proteína e lipídeos, a geleia apresentou valores de $0,21,0,23$ e 0,06 g. $100 \mathrm{~g}^{-1}$, respectivamente, tais valores são inferiores aos encontrados por Miguel et al. (2008), para fração de cinzas, proteína e lipídeos de geleia de elaborada com sobras de polpa de melão que são $0,45,0,80$ e $0,07 \mathrm{~g} \cdot 100 \mathrm{~g}^{-1}$, respectivamente.

O suco da casca do abacaxi, para a confecção da geleia, apresentou $97 \%$ de umidade, $3,7^{\circ}$ Brix, 0,92 g de ácido cítrico. $100 \mathrm{~g}^{-1}$ e $3,5 \mathrm{de} \mathrm{pH}$. A geleia depois de confeccionada apresentou $36,5 \%$ de umidade, 54,8 ㅇ Brix, $0,51 \mathrm{~g}$ de ácido cítrico. $100 \mathrm{~g}^{-1}$ e $3,6 \mathrm{de} \mathrm{pH}$. Sabe-se que a acidez e o $\mathrm{pH}$ das geleias devem ser controlados. A acidez total não deve exceder a 0,8\%, e o mínimo indicado é de 0,3\%. Quanto ao $\mathrm{pH}$, sugere-se um $\mathrm{pH}$ máximo de 3,4, sendo que abaixo de 3,0 ocorre uma tendência à sinérese (Lago, Gomes \& Silva, 2006). A geleia do suco da casca de abacaxi apresentou-se em conformidade com estes valores.

De acordo com a caracterização inicial da geleia, verifica-se que os valores de sólidos solúveis estão abaixo do estipulado pela legislação, mínimo de $65^{\circ}$ Brix para a geleia tipo extra e pouco acima do valor máximo de $35 \%$ de umidade, estabelecido para geleia do tipo extra (Brasil, 1978), pois o objetivo deste trabalho foi elaborar uma geleia de menor consistência. Porém, ela foi preparada respeitando-se a proporção de cinquenta partes de suco de fruta e cinquenta partes de sacarose, estabelecida pela Resolução 12/78 da Comissão Nacional de Normas e Padrões para Alimento (CNNPA) para este tipo de geleia (Brasil, 1978). 
Quanto às análises microbiológicas, as partes do abacaxi bem como seus produtos apresentaram ausência de qualquer microrganismo (coliformes, Staphylococcus e Salmonella) que pudesse a vir causar algum tipo de contaminação, já para a geleia os valores de microoganismos (bolores e leveduras) encontrados foram abaixo dos permitidos pela RDC $\mathrm{n} 012$ de 02/01/2001 que dispõe sobre definição de critérios e padrões microbiológicos para alimentos (Brasil, 2001).

\subsection{Avaliação sensorial}

Diversos fatores influenciam na qualidade de doces, inclusive no sabor destes. Dentre estes fatores estão o tipo de tratamento e os parâmetros do processo aos quais as frutas são submetidas (Sato \& Cunha, 2005). De acordo com Dutcosky (2007), a qualidade do alimento compreende três aspectos fundamentais: nutricional, sensorial e microbiológico. As características de qualidade sensorial, tais como sabor, textura e aparência, precisam ser monitoradas desde o momento da percepção e escolha desta qualidade, por meio de estudos de consumidor.

Em relação à análise sensorial, o doce pastoso (Doce 1 ) obteve uma boa aceitação que pode ser evidenciada com os dados de preferência pelo sabor e aparência. Em relação a sabor, do total de provadores, a maioria dos provadores (55\%) gostaram e $29 \%$ gostaram muito, em que apenas $9 \%$ disseram ser indiferentes e $7 \%$ disseram não gostar, tendo como aceitação global uma média de $84 \%$. Em relação à aparência, a maioria dos provadores também disseram gostar da aparência (54\%) e $14 \%$ gostaram muito, porém $25 \%$ disseram ser indiferentes e apenas $7 \%$ não gostaram, tendo como aceitação global uma média de $68 \%$.

Dos 88 provadores, $57 \%$ eram do sexo masculino e $43 \%$ do sexo feminino. Em relação a variável sabor (Figura 1-a), é possível verificar que entre os provadores do sexo feminino e masculino houve uma aceitação global de $87 \%$ e $84 \%$, respectivamente, sendo que apenas $5 \%$ do público feminino e $6 \%$ do público masculino não gostaram do sabor do doce. Enquanto que em relação a variável aparência (figura 1-b), é possível verificar que entre os provadores do sexo feminino e masculino houve uma aceitação global de $68 \%$ e $70 \%$, respectivamente, sendo que $8 \%$ dos provadores do sexo feminino e $4 \%$ do sexo masculino não gostaram da aparência, não houve ninguém que desgostasse muito do Doce 1 , quanto ao sabor ou aparência.

A faixa etária dos provadores foi de 15 a acima de 60 anos, sendo que $69 \%$ encontravamse entre 15 e 30 anos, 24\% encontravam-se entre 30 e 45 anos e $7 \%$ de 45 a acima de 60 anos. Em relação a variável sabor (Figura 1-c), a faixa etária entre 15 e 30 anos mostrou uma aceitação global de $57 \%$, enquanto as demais faixas compreenderam uma aceitação global de $27 \%$, em que a opinião mais evidenciada foi a 'gostei'. Já em relação a variável aparência (Figura 1-d), a faixa etária entre 15 e 30 anos mostrou uma aceitação global de $47 \%$, enquanto as demais faixas compreenderam uma aceitação global de $24 \%$, em que a opinião mais evidenciada foi a 'gostei'. 

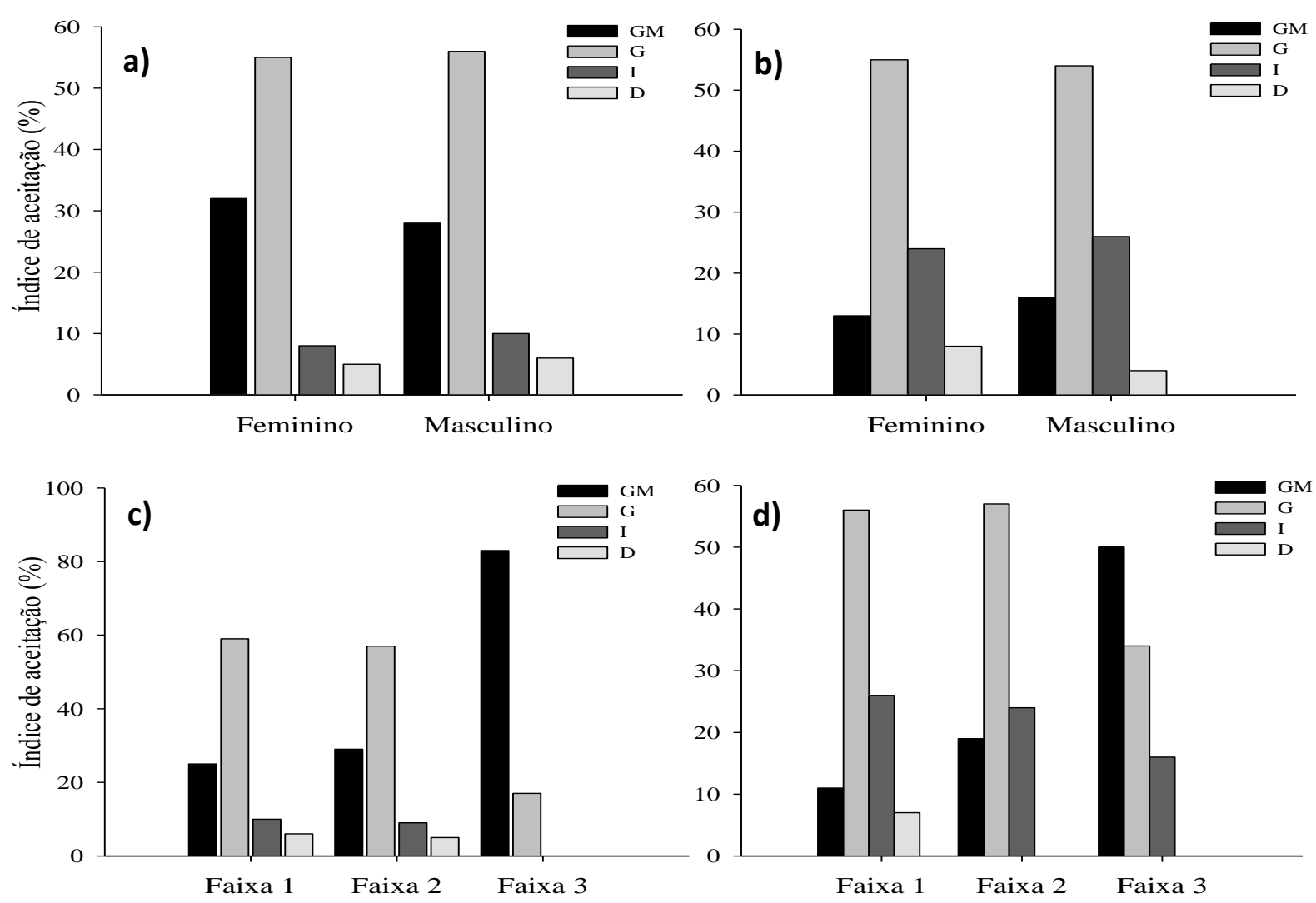

Figura 1: Índice de aceitação (\%) do doce pastoso da casca do abacaxi entre os provadores. a) sexo masculino e feminino, em relação ao sabor, b) sexo masculino e feminino, em relação à aparência, c) faixas etárias, em relação ao sabor e d) faixas etárias, em relação à aparência. Faixa 1-15 a 30 anos, Faixa 2-31 a 45 anos e Faixa 3 - 46 a acima de 60 anos. GM - gostei muito, G - gostei, I - indiferente, D - desgostei.

Em relação à análise sensorial, o doce de enrolar (Doce 2) obteve uma boa aceitação que pode ser evidenciada com os dados de preferência pelo sabor e aparência. Em relação ao sabor, do total de provadores $49 \%$ gostaram e $44 \%$ gostaram muito, em que apenas $6 \%$ disseram ser indiferentes e 1\% disseram não gostar, tendo como aceitação global uma média de 93\%. Em relação à aparência, do total de provadores $48 \%$ gostaram e $46 \%$ gostaram muito, porém $5 \%$ disseram ser indiferentes e apenas $1 \%$ não gostaram, tendo como aceitação global uma média de $94 \%$.

Dos 85 provadores, $55 \%$ eram do sexo masculino e $45 \%$ do sexo feminino. Em relação a variável sabor (Figura 2-a), é possível verificar que entre os provadores do sexo feminino e masculino houve uma aceitação global de $97 \%$ e $89 \%$, respectivamente, sendo que apenas $2 \%$ do público masculino não gostaram e do público feminino não houve ninguém que desgostasse do sabor do doce. Enquanto que em relação a variável aparência (figura 2-b), é possível verificar que entre os provadores do sexo feminino e masculino houve uma aceitação global de $97 \%$ e $91 \%$, respectivamente, sendo que apenas $2 \%$ do público masculino não gostaram e do público feminino não houve ninguém que desgostasse da aparência do doce, não houve ninguém que desgostasse muito do Doce 2, quanto ao sabor ou aparência. 
A faixa etária dos provadores foi de 15 a acima de 60 anos, sendo que $60 \%$ encontravamse entre 15 e 30 anos, 25\% encontravam-se entre 30 e 45 anos e 15\% de 45 a acima de 60 anos. Em relação a variável sabor (Figura 2-c), a faixa etária entre 15 e 30 anos mostrou uma aceitação global de 53\%, enquanto as demais faixas compreenderam uma aceitação global de $40 \%$, em que a opinião mais evidenciada foi a 'gostei'. Já em relação a variável aparência (Figura 1-d), a faixa etária entre 15 e 30 anos mostrou uma aceitação global de $56 \%$, enquanto as demais faixas compreenderam uma aceitação global de $38 \%$, em que a opinião mais evidenciada foi a 'gostei' .
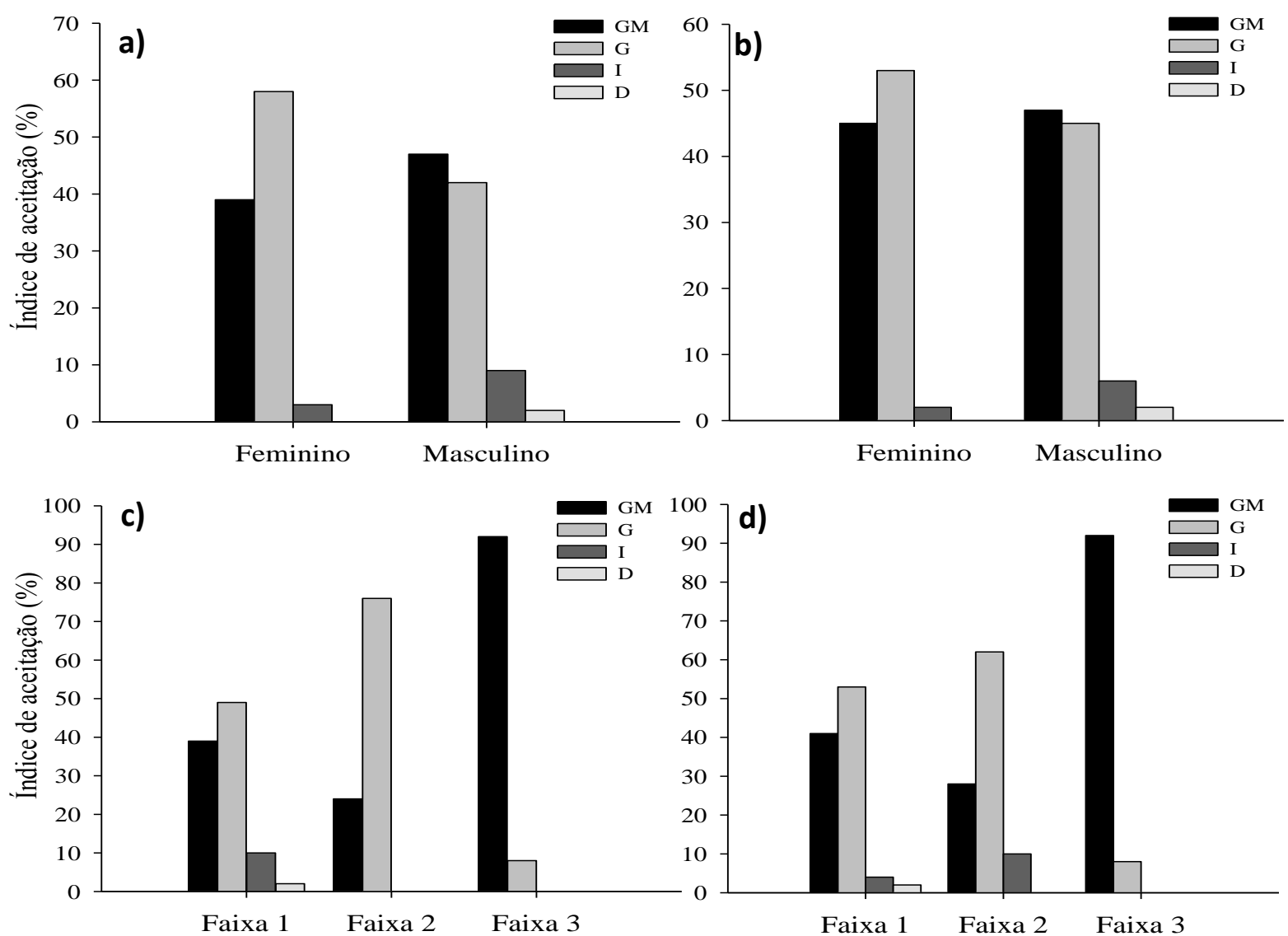

Figura 2: Índice de aceitação (\%) do doce de enrolar da casca do abacaxi entre os provadores. a) sexo masculino e feminino, em relação ao sabor, b) sexo masculino e feminino, em relação à aparência, c) faixas etárias, em relação ao sabor e d) faixas etárias, em relação à aparência. Faixa 1 - 15 a 30 anos, Faixa 2 - 31 a 45 anos e Faixa 3 - 46 a acima de 60 anos. GM - gostei muito, G - gostei, I - indiferente, D - desgostei.

A geleia também obteve uma boa aceitação que pode ser evidenciada com os dados de preferência pelo sabor e intenção de compra. Em relação ao sabor, do total de provadores, 55\% gostaram, $41 \%$ gostaram muito, e apenas 3\% disseram ser indiferentes, tendo uma aceitação global de $96 \%$.

Dos 65 provadores, $38 \%$ eram do sexo masculino e $62 \%$ do sexo feminino. Em relação a variável sabor (Figura 3-a), é possível verificar que entre os provadores do sexo feminino e masculino houve uma aceitação global de $95 \%$ e $100 \%$, respectivamente, sendo que apenas $5 \%$ 
do público feminino foram indiferentes ao sabor, sendo que não houve ninguém que desgostasse do sabor da geleia. A faixa etária dos provadores foi de 15 a acima de 60 anos, sendo que 57\% encontravam-se entre 15 e 30 anos, 31\% encontravam-se entre 30 e 45 anos e $12 \%$ de 45 a acima de 60 anos. Em relação a variável sabor (Figura 2-c), a faixa etária entre 15 e 30 anos mostrou uma aceitação global de $57 \%$, enquanto as demais faixas compreenderam uma aceitação global de $41 \%$, em que a opinião mais evidenciada foi a 'gostei', apenas $25 \%$ dos provadores que consistiam a faixa etária 3 disseram ser indiferentes ao sabor da geleia.
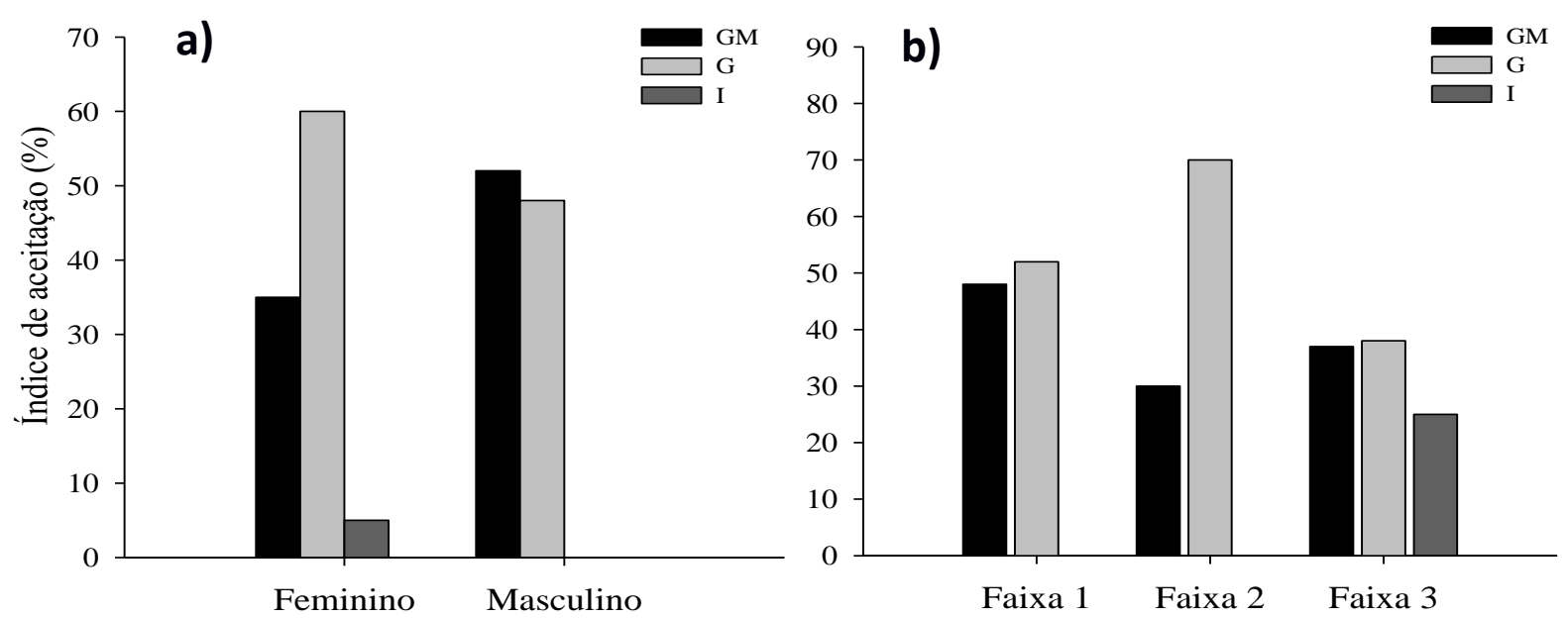

ura 3: Índice de aceitação (\%) da geleia da casca do abacaxi entre os provadores. a) sexo masculino e feminino, em relação ao sabor e b) faixas etárias, em relação ao sabor. Faixa 1 - 15 a 30 anos, Faixa 2 - 31 a 45 anos e Faixa 3 46 a acima de 60 anos. GM - gostei muito, G - gostei, I - indiferente, D - desgostei.

Em função dos dados obtidos, é possível perceber que o sabor foi a característica mais atrativa dos produtos confeccionados com o resíduo de abacaxi 'Pérola', sendo que o que teve maior índice de aceitação foi a geleia, seguida pelo doce de enrolar e doce pastoso, enfatizando uma boa aceitabilidade por parte dos consumidores.

De acordo com Teixeira, Meinert \& Barbetta. (1987) e Souza, Novello, Almeida \& Quintiliano (2007) para que um produto seja considerado aceito, em termos de suas propriedades sensoriais, é necessário que obtenha um índice de aceitabilidade de, no mínimo, 70\%. Senso assim, todos os produtos confeccionados com o resíduo da casca de abacaxi apresentaram um bom índice de aceitação global (acima de $80 \%$ ), semelhantes aos dados obtidos por Santana \& Oliveira (2005) que obtiveram $84,2 \%$ de aceitação para o doce cremoso de melancia com coco.

Portanto o uso de processo artesanal tradicional para a produção de doces cremosos e geleias com o resíduo da casca de abacaxi é viável, pois segundo Santana \& Oliveira (2005) esse processo torna-se viável economicamente por ser a matéria-prima culturalmente desperdiçada pela população e indústria. Em que o aproveitamento integral dos alimentos é uma nova vertente na área de alimentação que precisa ter maior veiculação, cuja informação ainda é escassa. 


\section{CONCLUSÃO}

O aproveitamento da casca de abacaxi na alimentação humana apresenta-se como uma boa alternativa, pois contém quantidades muito próximas às da polpa de matéria mineral, proteína bruta e lipídeos e maior teor de fibras ao da polpa, além do menor valor calórico. Além disso, o suco extraído da casca apresentou também baixo teor de carboidratos e calorias, além de apresentar boas quantidades de matéria mineral, proteína bruta e lipídeos, podendo também ser indicado para consumo direto ou na confecção de doces, geleias ou bolos.

De maneira geral, os doces e a geleia confeccionados com os resíduos da casca de abacaxi minimamente processado teve uma boa aceitabilidade oferece uma alternativa para 0 aproveitamento da casca.

\section{AGRADECIMENTOS}

Os autores agradecem à FAPEMIG (Fundação de Amparo à Pesquisa do estado de Minas Gerais) pelo financiamento do projeto (APQ-00926-09).

\section{REFRÊNCIAS}

AOAC. (2012) Association of Official Analytical Chemistry. Official methods of analysis. (19 ${ }^{\text {th }}$ ed). Gaithersburg, MD: AOAC International.

Bleinroth, E. W. (1978) Matéria-prima. In: Medina, J. C.; Bleinroth, E. W.; Martin, Z. J.; Souza Junior, A. J., Lara, J. C., Hashizumet, T., Moretti, V. A., Marques, J. F. Abacaxi: da cultura ao processamento e comercialização (69-94). Campinas: ITAL.

Borges, C. D., Chim, J. F., Leitão, A. M., Pereira, E. \& Luvielmo, M. M. (2004) Produção de Suco de Abacaxi Obtido a Partir dos Resíduos da Indústria Conserveira. Boletim CEPPA, 22(1), 23-34.

Botelho, L.; Conceição, A. \& Carvalho, C.V. (2002) Caracterização de fibras alimentares da casca e cilindro central do abacaxi 'smooth cayenne'. Ciência e Agrotecnologia, 26(2), 362-367.

Brasil. (1978) Ministério da Saúde. Agência Nacional de Vigilância Sanitária. Resolução no 12 da Comissão Nacional de Normas e Padrões para Alimentos - CNNPA, de 24 julho. Recuperado de http://portal.anvisa.gov.br/documents/33916/394219/Resolucao_CNNPA_n_12_de_1978.pdf /4f93730f-65b8-4d3c-a362-eae311de5547

Brasil. (2001) Ministério da Saúde. Agência Nacional de Vigilância Sanitária. Resolução no 12, de 2 de janeiro de 2001 - Definição de critérios e padrões microbiológicos para alimentos. Recuperado de http://portal.anvisa.gov.br/documents/33880/2568070/RDC_12_2001.pdf/15ffddf6-37674527-bfac-740a0400829b

Brasil. (2012) Ministério da Saúde. Agência Nacional de Vigilância Sanitária. Resolução no 54, de 12 de novembro de 2012 - Regulamento técnico sobre informação nutricional complementar. Brasilia, DF: Diário Oficial [da] República Federativa do Brasil, Poder Executivo.

Castro, M. H.C. A. (2002) Fatores determinantes de desperdício de alimentos no Brasil: Diagnóstico da situação. (Monografia de especialização em Gestão de Qualidade em Serviços de Alimentação) Universidade Estadual do Ceará, Fortaleza, CE. 
Ceagesp. (2000) Companhia de Entrepostos e Armazéns Gerais de São Paulo. Classificação do abacaxi (Ananas comosus (L.) Merril). Recife: Centro de qualidade em Horticultura, CEAGESP. Folder.

Costa, J. M. C., Felipe, E. M. F., Maia, G. A., Brasil, I. M. \& Hernandez, F. F. H. (2007) Comparação dos parâmetros físico-químicos e químicos de pós alimentícios obtidos de resíduos de abacaxi. Revista Ciência Agronômica, 38(2), 228-232.

Crestani, M., Barbieri, R. L., Hawerrothl, F. J., Carvalho, F. I. F. \& Oliveira, A. C. (2010) Das Américas para o Mundo - origem, domesticação e dispersão do abacaxizeiro. Ciência Rural, 40(6), 1473-1483.

Damiani, C., Silva, F. A., Rodovalho, E. C., Becker, F. S., Asquieri, E. R., Oliveira, R. A. \& Lage, M. E. (2011) Aproveitamento de resíduos vegetais para produção de farofa temperada. Alimentos $e$ Nutrição, 22(4), 657-662.

Dutcosky, S. D. (2007) Análise sensorial de alimentos. (2ae ed.) Curitiba, PR: Champagnat.

Ferreira, D. F. (2011) Sisvar: a computer statistical analysis system. Ciência e Agrotecnologia, 35(6), 1039-1042. doi: 10.1590/S1413-70542011000600001

Gonçalves, N. B. \& Carvalho, V. D. (2000) Características da fruta. In: GONÇALVES, N. B.(Org.) Abacaxi: pós-colheita (13-27). Brasília, DF: Embrapa Comunicação para Transferência de Tecnologia (Frutas do Brasil, 5).

Gondim, J. A. M., Moura, M. F. V., Dantas, A. S., Medeiros, R. L. S. \& Santos, K. M. (2005) Composição centesimal e de minerais em cascas de frutas. Ciência e Tecnologia de Alimentos, 25(4), 825-827. doi: 10.1590/S0101-20612005000400032

Goubart, R. (1979) Tecnologia do doce em pasta. (n. 10-11) Florianópolis, SC: Boletim informativo da SBCTA - Sociedade brasileira de ciência e tecnologia de alimentos.

Kamer, J. H. V. \& Ginkel, L. V. (1952) Rapid determition of crude fiber in cereals. Cereal Chemistry, 29(4), 239-251.

Lago, E. S., Gomes, E. \& Silva, R. (2006) Produção de geleia de jambolão (Syzygium cumini lamarck): processamento, parâmetros físico - químicos e avaliação sensorial. Ciência e Tecnologia de Alimentos, 26(4), 847-852. doi: 10.1590/S0101-20612006000400021

Meilgaard, M., Civille, G. V. \& Carb, B. T. (1999) Sensory evaluation techniques. (3a ed.) New York: CRC Press.

Miguel, A. C. A., Albertini, S., Begiato, G. F., Dias, J. R. P. S. \& Spoto, M. H. F. (2008) Aproveitamento agroindustrial de resíduos sólidos provenientes do melão minimamente processado. Ciência e Tecnologia de Alimentos, 28(3), 733-737. doi: 10.1590/S010120612008000300033

Moretti, C. M. \& Machado, C. M. M. (2006) Aproveitamento de resíduos sólidos do processamento mínimo de frutas e hortaliças (25-32). Piracicaba, SP: Encontro Nacional sobre processamento mínimo de frutas e hortaliças - USP/ESALQ.

Nepa. (2011) Núcleo de Estudos e Pesquisas em Alimentação da UNICAMP. Tabela brasileira de composição de alimentos. Campinas, SP: TACO.

Osborne, D. R. \& Voogt, P. (1978) The analysis of nutrient in foods. London: Academic Press. 
Rogério, M. C. P., Borges, I., Neiva, J. N. M., Rodriguez, N. M., Pimentel, J. C. M., Martins, G. A., Ribeiro, T. P., Costa, J. B., Santos, S.F. \& Carvalho, F. C. (2007) Valor nutritivo do resíduo da indústria processadora de abacaxi (Ananas comosus L.) em dietas para ovinos. 1. Consumo, digestibilidade parente e balanços energético e nitrogenado. Arquivos Brasileiros de Medicina Veterinária e Zootecnia, 59(3), 773-781. doi: 10.1590/\$0102-09352007000300032

Santana, A. F. \& Oliveira, L. F. (2005) Aproveitamento da casca de melancia (Curcubita citrullus, shrad) na produção Artesanal de doces alternativos. Alimentos e Nutrição, 16(4), 363-368.

Santos, A. R. R., Ciabotti, S., Pereira, J. M. A., Gonçalves, C. A. A. \& Campagnol, P. C. B. (2010) Avaliação da composição centesimal de casca de abacaxi (1-4). III Seminário de Iniciação Científica e Inovação Tecnológica. Recuperado de http://www.iftm.edu.br/proreitorias/pesquisa/3o_seminario/trabalhos/ali_avaliacao_da_com posicaoo_centesimal.pdf

Sarzi, B., Durigan, J. F. \& Rossi Junior, O. D. (2002) Temperatura e tipo de preparo na conservação de produto minimamente processado de abacaxi 'Pérola'. Revista Brasileira de Fruticultura, 24(2), 376-380. doi: 10.1590/S0100-29452002000200020

Sato, A. C. K. \& Cunha, R. L. (2005) Avaliação da cor, textura e transferência de massa durante o processamento de goiabas em calda. Brazilian Journal Food Technology, 8(2), 149-156.

Silva, N., Junqueira, V. C. A. \& Silveira, N. F. A. (2007) Manual de métodos de análise microbiológica de alimentos. (3a ed.) São Paulo, SP: Livraria Varela.

Souza, P. D. J., Novello, D., Almeida, J. M. \& Quintiliano, D. A. (2007) Análise sensorial e nutricional de torta salgada elaborada através do aproveitamento alternativo de talos e cascas de hortaliças. Alimentos e Nutrição, 18(1), 55-60.

Teixeira, E., Meinert, E. \& Barbetta, P. A. (1987) Análise sensorial de alimentos. Florianópolis, SC: Editora UFSC.

Waughon, T. G. M. \& Pena, R. S. (2006) Estudo da secagem da fibra residual do abacaxi. Alimentos e Nutrição, 17(4), 373-379. 